\title{
PREDICTION FOR IRREGULAR OCEAN WAVE AND FLOATING BODY MOTION BY REGULARIZATION: PART 2. MOTION PREDICTION
}

\begin{abstract}
Summary
In the analysis of the motion of a floating body, the domains can broadly be divided into the frequency domain and the time domain. The essence of the frequency domain analysis lies in calculating the hydrodynamic coefficient from the equation of motion, which has six degrees of freedom, by applying several methods. In this research, Bureau Veritas's "HydroStar" software was used, and the comparison and the verification were carried out by experiments. For the time domain analysis, we used an existing method proposed by Cummins and made motion predictions by using deterministic random phases calculated in the time domain calculations of the excitation force. Lastly, the potential of wave and motion predictions was verified through the data obtained from a motion analysis experiment using a tension leg platform in the context of irregular waves.
\end{abstract}

Key words: $\quad$ deterministic random phase, floating body motion, Cummins method, ocean wave, prediction, regularization, L-curve.

\section{Introduction}

In the ocean, vessels and floating bodies oscillate due to ocean waves. Complicated motions can be divided into six degrees of freedom based on rectangular coordinates, defined by translational motions in the $x_{-}, y_{-}$, and z-directions (surge, sway, heave) and rotational motions (roll, pitch, yaw).

The motion performance of vessels and floating bodies is evaluated according to motion modes, assuming that waves are regular and that incident waves have a unit amplitude, and the Response Amplitude Operator (RAO) is obtained for each frequency. Under the assumption of a linear system, the RAO can be calculated once to obtain responses to a particular incident wave, and in the case of irregular waves, the motion spectrum for each mode of motion can be calculated from the wave spectrum and the RAO.

In traditional naval architecture and ocean engineering, motion performance has been evaluated and analysed in the frequency domain, and methods to calculate fluid force coefficients included the panel method, which involves the strength of the source, and the Green function. Recent introductions of large scale vessels such as FPSOs and drillships 
require additional seakeeping performance evaluations that take various marine environments, moorage, external force conditions, and multibody interactions into consideration. Solving these problems requires new methods due to limitations in current methods, and one representative method is the vessel motion analysis in the time domain.

A representative method of motion analysis in the time domain is that proposed by Cummins [1]. This method expresses a hydrodynamic force as the sum of the impulsive and the memory terms, where the memory terms are expressed by the impulsive response function and the convolution integral of the body's relative speed. In particular, there has even been a study on a method of calculation that uses a differential equation instead of directly solving the convolution integral, which is highly time-consuming (Söding [2]).

This paper discusses analyses in the frequency domain and in the time domain. For the analysis in the frequency domain, the commercial software from Bureau Veritas called "HydroStar" and an in-house code called "SOSMAT" (Ship \& Offshore Structure Motion Analysis Tool) were used. Fluid force coefficients and RAOs obtained from the experimental methods were compared to the values acquired from the software calculations.

In the time domain analysis, the deterministic phase obtained in Part 1 of this paper is used in time series calculations of the exciting force, and the Cummins Method is used to calculate the motion in time series for each mode. Motion prediction is possible because the method uses the deterministic phase calculated from the elevation of the wave gauge separated in the direction of the incident wave. In addition, the calculated values of the predictable area are used to increase the accuracy in the motion prediction.

\section{Equation of motion}

\subsection{Mass-spring-damper system}

The well-known Newton's 2nd law of motion is as follows (Symon [3]):

"The rate of change of momentum is proportional to the impressed force, and is in the direction in which the force acts"

$$
m \ddot{x}=F
$$

where $m$ is the object's mass, which in this paper is the mass, $M$, of a vessel or a floating body, $\ddot{x}$ is the acceleration of the object, and $F$ is the force acting on the object.

Moreover, the application of this law on mass-spring-damper systems similar to those of vessels or floating bodies requires that added mass $M_{a}$, radiation damping $C_{r}$, viscous damping $C_{v}$, restoring $K$, and excitation force $F_{E}$ are also taken into consideration.

Such considerations can be expressed as eq. (1) as shown below:

$$
\left(M+M_{a}\right) \ddot{x}+\left(C_{r}+C_{v}\right) \dot{x}+K x=F_{E} .
$$

\subsection{Time domain approach}

Cummins [1] introduced a method for the time domain motion analysis using the impulse response function. The impulse response function transforms the hydrodynamic coefficient in the frequency domain into the diffraction force and the radiation force in the time domain. Using a convolution integral, the radiation force that causes motion in floating bodies can be expressed as follows:

$$
F_{R}=-M_{a}(\infty) \ddot{x}-\int_{-\infty}^{t} R(t-\tau) \dot{x}(\tau) \mathrm{d} \tau
$$


where $M_{a}(\infty)$ is the added mass with infinite frequency, which is replaced by the end value in the frequency domain in the calculations. $R(t)$ is the retardation function, or time memory function, related to the radiation force. $M_{a}(\infty)$ and $R(t)$ are defined as follows:

$$
M_{a}(\infty)=M_{a}(\omega)+\frac{1}{\omega} \int_{0}^{\infty} R(t) \sin (\omega) \mathrm{d} t
$$

and

$$
R(t)=\frac{2}{\pi} \int_{0}^{\infty} C_{r}(\omega) \cos (\omega t) \mathrm{d} \omega
$$

where $M_{a}(\omega)$ is the added mass, and $C_{r}(\omega)$ is the radiation damping.

Finally, the equation of motion of the vessel in the time domain, using the FroudeKrylov force and the restoring force is as follows:

$$
\left(M+M_{a}(\infty)\right) \ddot{x}+\int_{-\infty}^{t} R(t-\tau) \dot{x}(\tau) \mathrm{d} \tau+K x=F_{E}(t) .
$$

In addition, the excitation force in the time domain is as follows (Journée [4], Lee [5], Clauss [6], and Kosleck[7]):

$$
F_{E}(t)=\sum_{p=1}^{M} A_{p} L\left(\omega_{p}\right)\left\{e^{-i \omega_{p} t}\right\}\left\{e^{i \varphi_{p}}\right\}
$$

where $A$ is the incident wave amplitude, $L$ is the exciting force on the unit incident wave amplitude, and the equation is called "Linear Transfer Function (LTF)". $\varphi_{p}$ is the deterministic random phase which can be calculated from Part 1.

2.3 Numerical approach

The integration from $t_{n}$ to $t_{n+1}$ yields:

$$
x^{(n+1)}=x^{(n)}+\int_{n}^{n+1} f(x, \mathrm{t}) \mathrm{d} t
$$

where

$$
\frac{\mathrm{d} x}{\mathrm{~d} t}=f(x, t)
$$

Rearranging Eqs. (6) and (8) results in the following:

$$
\bar{M} \ddot{x}^{(n+1)}=\bar{M} \ddot{x}^{(n)}+\int_{n}^{n+1}\left(F_{E}+F_{C}\right) \mathrm{d} t-\int_{n}^{n+1} K x \mathrm{~d} t
$$

where

$$
\bar{M}=M+M_{a}(\infty),
$$

and

$$
F_{C}(t, \dot{x})=\int_{-\infty}^{t} R(t-\tau) \dot{x}(\tau) \mathrm{d} \tau
$$


The next approach is the numerical analysis approach, which includes the calculation of the displacement in the final time domain (Lee [5] and Gilat and Subramaniam [8]).

The Adams-Moulton method, a second-order formula is:

$$
\int_{n}^{n+1} x \mathrm{~d} t=\frac{\Delta t}{2}\left[x^{(n+1)}+x^{(n)}\right]
$$

Applying this equation to eqs. (8) and (10) the following equation is obtained:

$$
\bar{M} \dot{x}^{(n+1)}=\bar{M} \dot{x}^{(n)}+\frac{\Delta t}{2}\left[F_{E}^{(n+1)}+F_{E}^{(n)}+F_{C}^{(n+1)}+F_{C}^{(n)}\right]-\frac{\Delta t}{2} K\left[x^{(n+1)}+x^{(n)}\right]
$$

where

$$
\dot{x}^{(n+1)}=\frac{2}{\Delta t}\left[x^{(n+1)}-x^{(n)}\right]-\dot{x}^{(n)} .
$$

$F_{C}{ }^{(n+1)}$ is an unknown variable in the time iteration calculation, so it requires the previous time step information. The Adams-Bashfort method is thus introduced:

$$
\int_{n}^{n+1} F_{C} \mathrm{~d} t=\frac{\Delta t}{2}\left[3 F_{C}^{(n)}-F_{C}^{(n-1)}\right]
$$

Therefore, rearranging eqs. (14) to (17) results in the following:

$$
\left[\frac{4}{\Delta t^{2}} \bar{M}+K\right] \Delta x=\frac{4}{\Delta t^{2}} \bar{M} \dot{x}^{(n)}+\left[F_{E}^{(n+1)}+F_{E}^{(n)}\right]+\left[3 F_{C}^{(n)}+F_{C}^{(n-1)}\right]-2 K x^{(n)}
$$

where

$$
x^{(n+1)}=\Delta x+x^{(n)} .
$$

In summary, it is a process in which $\Delta x$ is calculated via the time step iteration, and the displacement $\mathrm{x}$ is updated. In particular, in the calculation of the retardation function, the magnitude of $\Delta t$ and the number of time domain components is important. This is because the convergence of damping can be confirmed by the number of time domain components, and due to limitations on computing time, it is important to use an appropriate number from the engineer's point of view. Although not discussed in this study, when additional radiation damping such as the sloshing effect occurs, the retardation function produces very sensitive results.

\section{Experimental result of motion prediction}

In this study, hydrodynamic coefficients and response amplitude operators (RAOs) for each mode were calculated from the motion analysis of floating-type offshore structures by using the commercial software, and the results were compared through experimental evaluations. In addition, as a core subject, for motion predictions on floating bodies, various types of equipment needed to measure waves and motion were set up, and the signal synchronization was used to validate the measurements. In particular, a system with a built-in trinocular camera was used for motion measurements, and several video cameras were used to record videos. 


\subsection{Experimental facility and instrument}

\subsubsection{Model}

The test model used in this study was a model of an offshore structure, type Tension Leg Platform (TLP), in the scale of 1:100. The designed displacement was $146 \mathrm{~kg}$, but the model's loading condition and the radius gyration were calculated with a weight reduction of $44 \mathrm{~kg}$, while the inside of the columns in the structure were left empty to facilitate weight distribution. The model is shown in Fig. 1 . $D_{\text {out }}$ is the distance outside the column, $D_{\text {in }}$ is the distance inside the column, $\mathrm{P}_{\mathrm{w}}$ is the pontoon width, $\mathrm{P}_{\mathrm{h}}$ is the pontoon height, $\mathrm{d}$ is the draft, and $\mathrm{f}$ is the free board. The body was composed of fibre reinforced plastic and stainless steel.

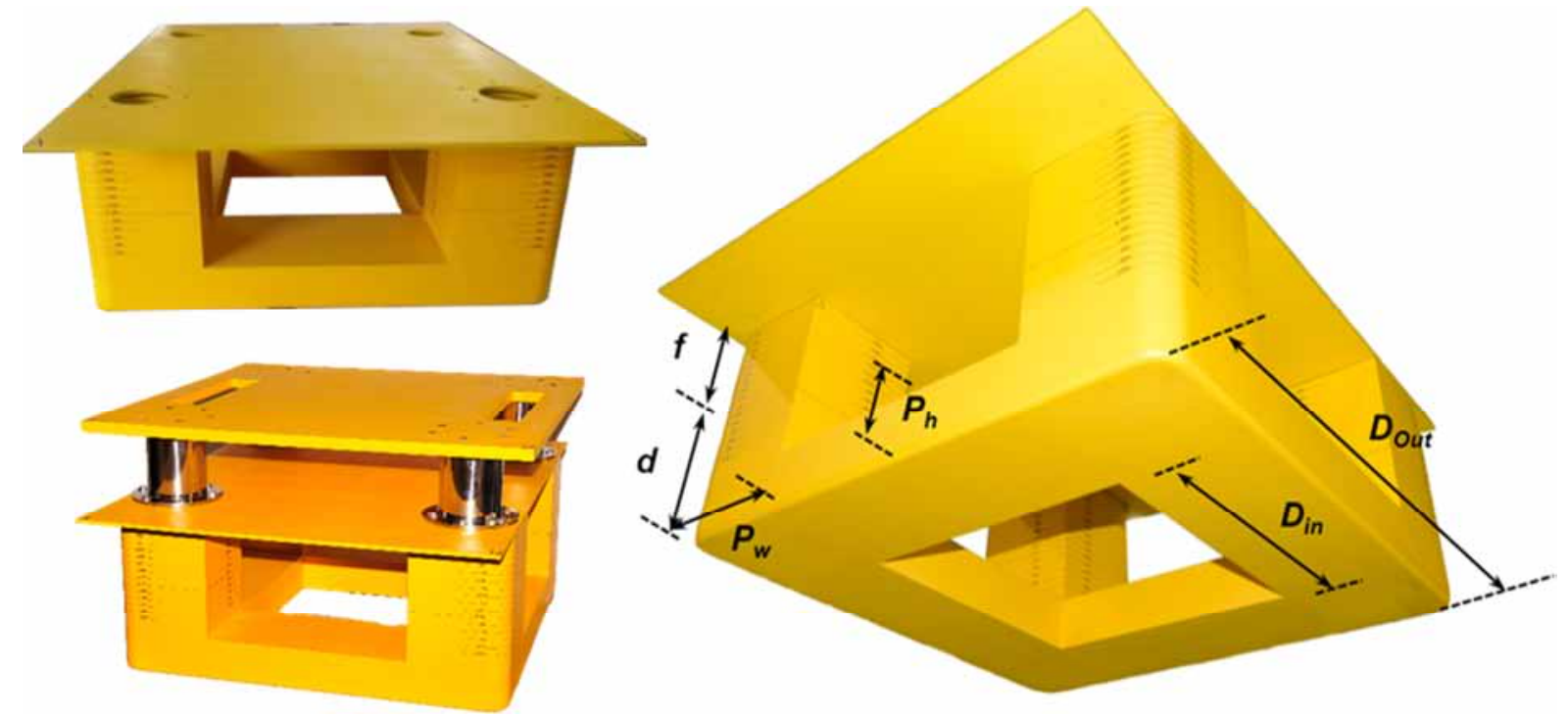

Fig. 1 Schematic view of the model

\subsubsection{Wave basin}

This experiment was performed in a three-dimensional wave basin at the National Fisheries Research and Development Institute (NFRDI) using the plunger-type wavemaker. Data on the wave basin, the wavemaker, and the towing carriage are shown in Figs. 2 and 3 and Table 1.

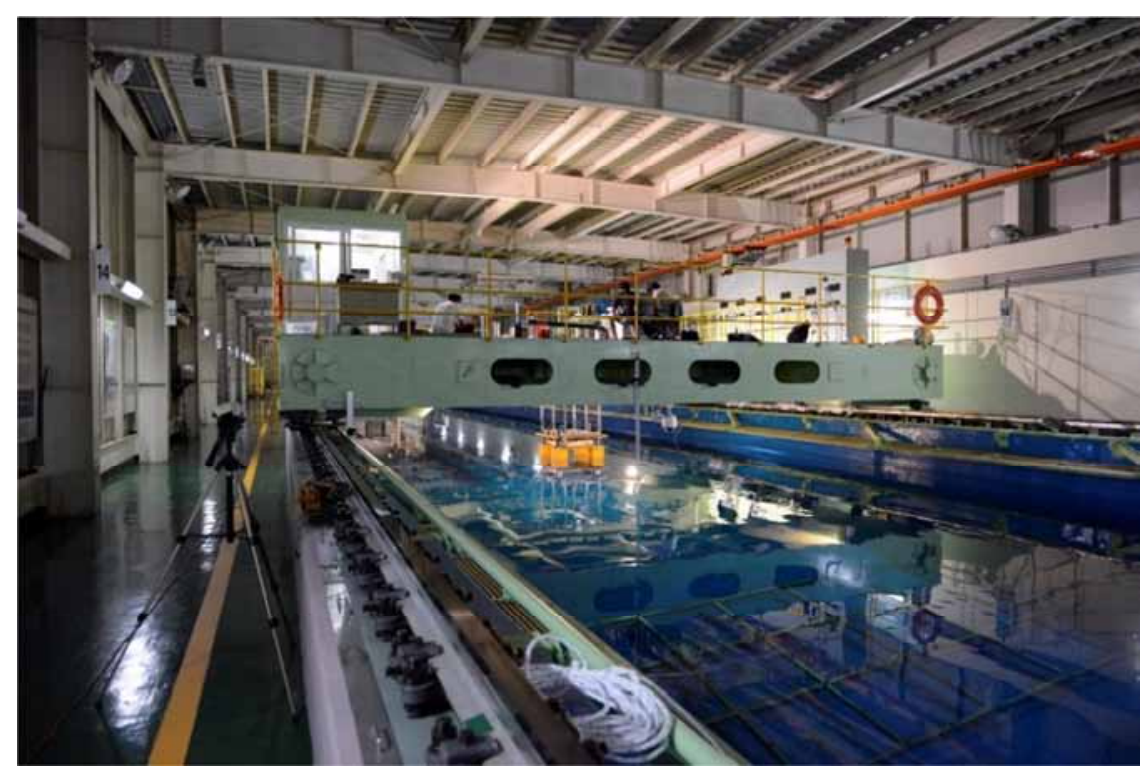

Fig. 2 Photo of the towing carriage with the TLP model 


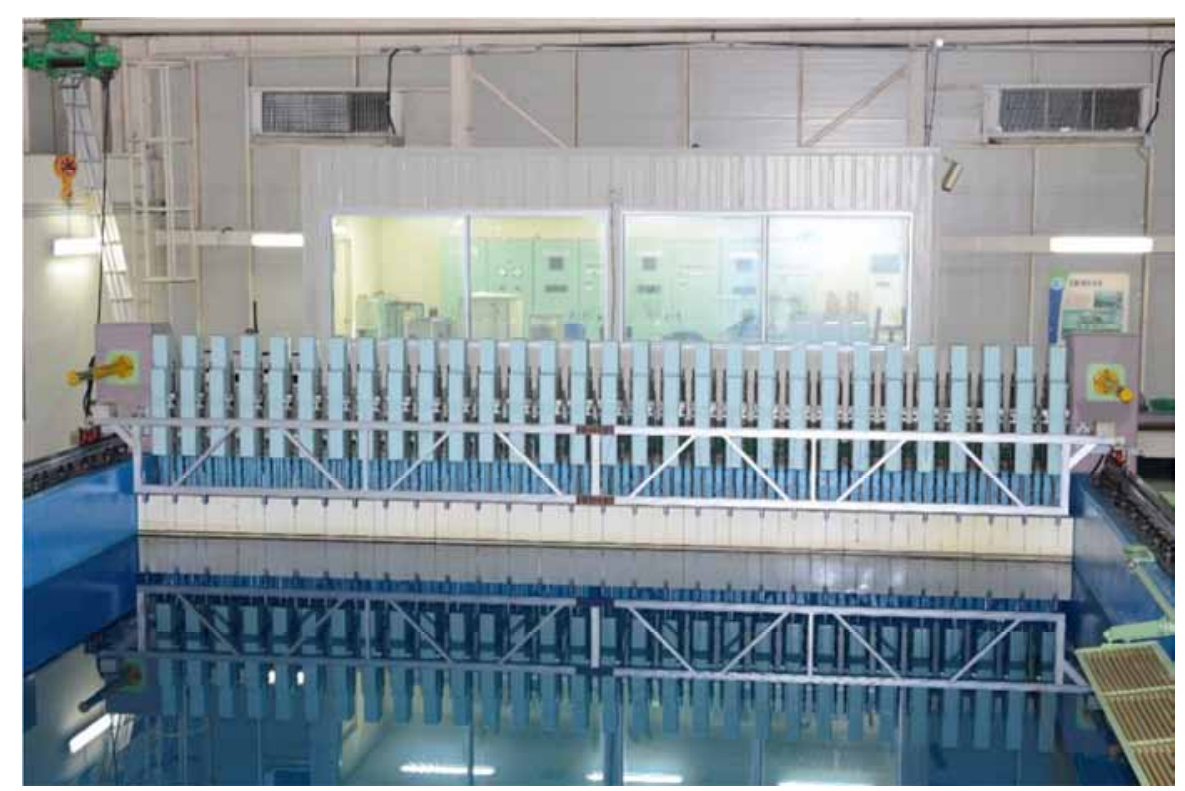

Fig. 3 Photo of the wavemaker and the control room

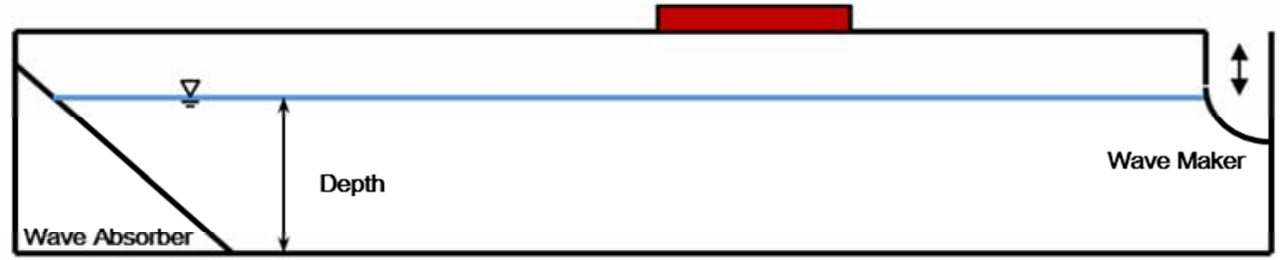

Length

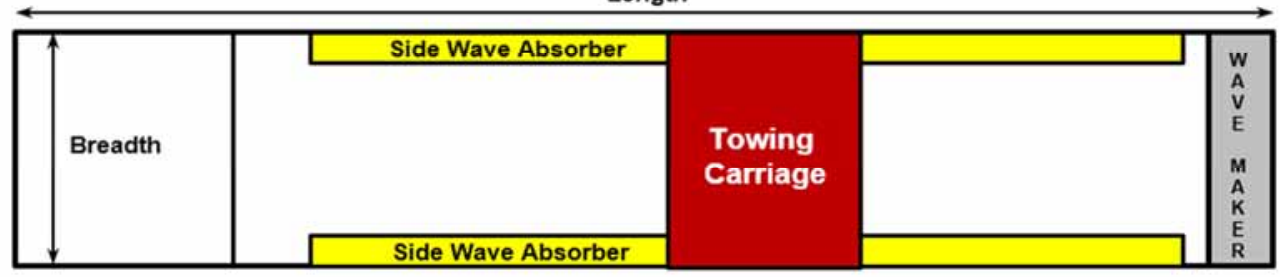

Fig. 4 Sketch of the wave basin and its towing carriage

Table 1 Specifications of the test model

\begin{tabular}{|c|c|}
\hline Type of wavemaker & Plunge \\
\hline Wave & Regular, irregular, unidirectional, multi directional \\
\hline Length & $85 \mathrm{~m}$ \\
\hline Breadth & $10 \mathrm{~m}$ \\
\hline Depth & $3.5 \mathrm{~m}$ \\
\hline Maximum wave height & $0.5 \mathrm{~m}$ \\
\hline Maximum wave period & $3 \mathrm{sec}$ \\
\hline
\end{tabular}

Table 2 Specifications of the towing carriage

\begin{tabular}{|c|c|}
\hline Weight & 38 ton \\
\hline Maximum speed & $3 \mathrm{~m} / \mathrm{s}$ \\
\hline Maximum acceleration & $0.6 \mathrm{~m} / \mathrm{s}^{2}$ \\
\hline Operation mode & Straight, meandering, PMM/CMT \\
\hline
\end{tabular}




\subsubsection{Six degrees of freedom optical tracking: motion measurement}

To measure the floating body's motions in its six degrees of freedom, a non-contact measurement method was used, along with a system with a built-in trinocular camera. We judged that the non-contact method was appropriate for this experiment because it does not require the installation of sensor cables and other equipment. The additional work of installing the panel with a wavemaker with respect to the coordinate system of the test model's centre of gravity was necessary. The wavemaker, which has a unique size, reflects the infrared light emitted by the trinocular camera system, allowing exposure of only the data needed by the system.

\subsubsection{Wave gauge}

In this experiment, there were two types of wave height meters, the resistance type and the capacitance type, which were used for the incidence wave case and for the periphery of the experimental model, respectively, to measure the corresponding waves.

\subsubsection{Data acquisition}

In this experiment, the National Instrument's USB-6343 BNC model was used for data acquisition, and the wave height meter output signals underwent the A/D transformation. The sampling rate used to collect data was $100 \mathrm{~Hz}$. A maximum of sixteen channels of analogue voltage could be entered.

\subsection{Setup}

\subsubsection{Experimental setup}

Since the purpose of this experiment was to moor a TLP type offshore structure and to evaluate its motion performance and predict motions of floating bodies, taking incident waves, the correct installation of the non-contact motion-measuring device and wave height meter, along with signal synchronization into consideration is essential.

The wave height meter was installed at a point $4.5 \mathrm{~m}$ in front of the model's centre of mass, as shown in Fig. 5. In addition, due to the calibrations carried out before the experiment, subtle environmental changes, such as water and air temperatures of the day, were reflected so as to maintain consistency.

The principle of the optical motion measurement device is to receive reflective signals from markers attached to the experimental body through the infrared lamp's light emission. Therefore, it is important to eliminate surrounding illumination and other potential sources of light.

Four-point or two-point spread mooring was done on the test model, depending on the heading change, and a total of four mooring lines were used. The process is schematized in Fig. 6, and the mooring line's spring constant is shown in Table 3. A free decay test was done on each of the two heading types while moored as shown in Fig. 7. Table 3 presents the results of the free decay test.

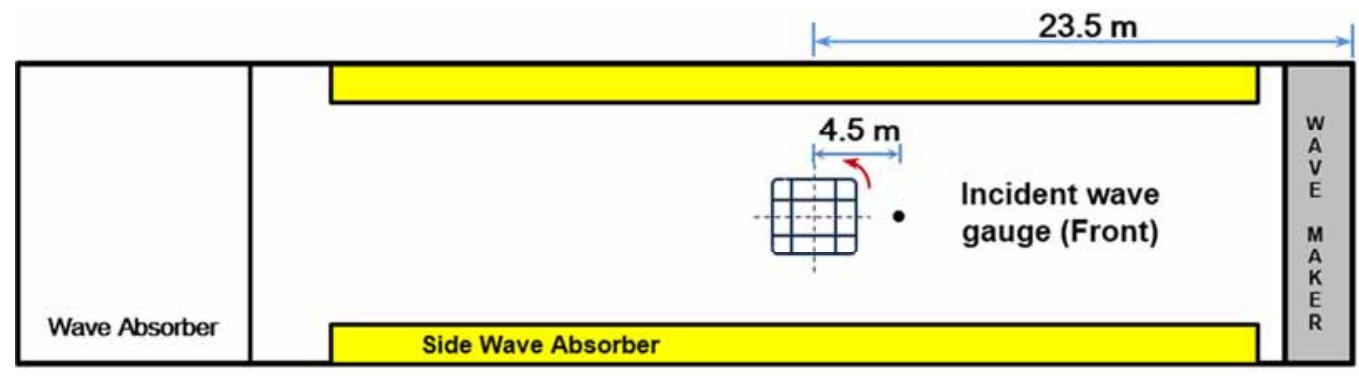

Fig. 5 Sketch of wave gauge position and experimental body 

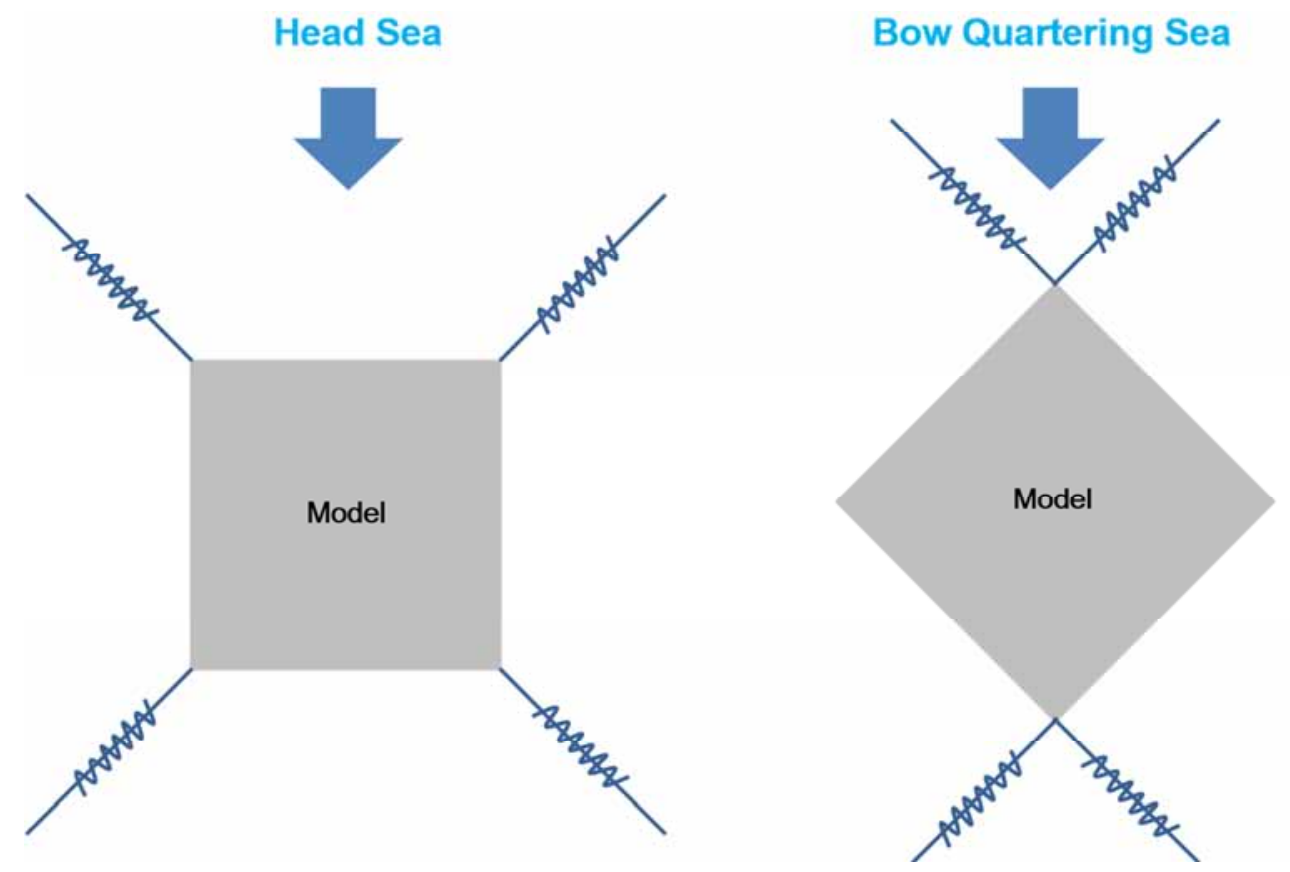

Fig. 6 Four-point and two-point mooring system (head sea, bow quartering sea)
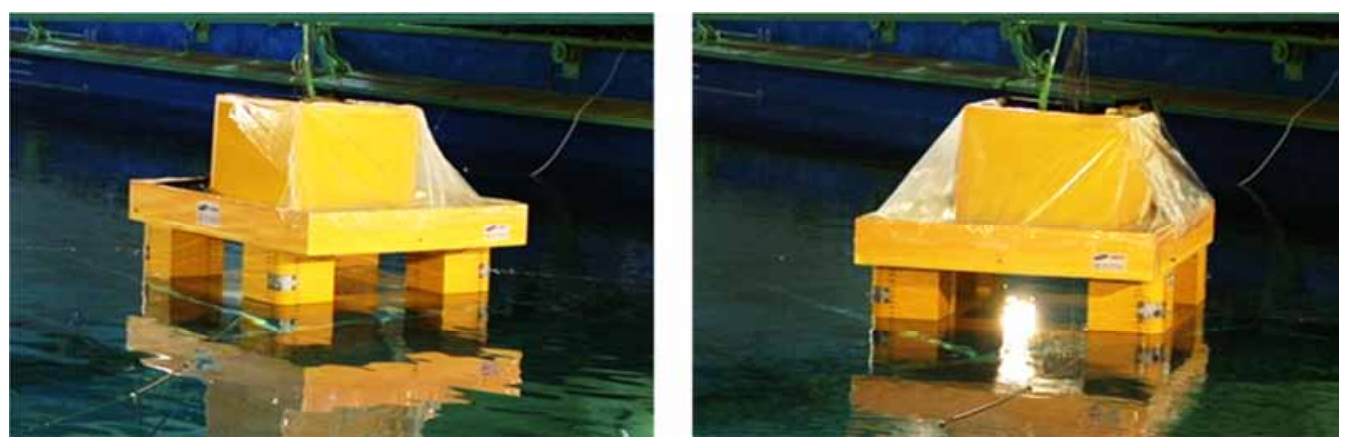

Fig. 7 Model setup (head sea, bow quartering sea)

\subsubsection{Wave condition}

Experimental waves were divided into regular waves and irregular waves, as shown in Tables 4 and 5.

For regular waves, the experiment was performed with the combination of wave steepnesses of 1/50,1/16,1/10, and periods between 7 and $16 \mathrm{~s}$ from the solid line, in order to examine the TLP motion properties with respect to the period and the wave height. In the regular wave experiment, motion responses with respect to the period emerge clearly, which is important for understanding motion characteristics.

The irregular wave was assumed to be uni-directional, and the experiment was repeated using random seeds on environmental conditions. The first environmental condition assumes a wave with a frequency of one occurrence per 1,000 years, with $H_{\mathrm{S}}=13.27 \mathrm{~m}$ and $T_{\mathrm{P}}=14.88 \mathrm{~s}$, while the second condition assumes a frequency of one occurrence per 10,000 years, with $H_{\mathrm{S}}=16.88 \mathrm{~m}$ and $T_{\mathrm{P}}=14.88 \mathrm{~s}$. In particular, ten random seeds were used in each wave calibration, and seeds 1 through 5 were used in each motion experiment.

All experiments were performed under the two wave conditions, head sea and quartering sea, and due to the nature of the TLP form, the beam sea condition was omitted. 
Table 3 Spring constant of mooring and results of the free decay test

\begin{tabular}{|c|c|r|r|r|r|}
\hline Heading & Item & \multicolumn{1}{c|}{ Surge } & \multicolumn{1}{c|}{ Heave } & \multicolumn{1}{c|}{ Roll } & \multicolumn{1}{c|}{ Pitch } \\
\hline \multirow{2}{*}{$180^{\circ}$} & Period [sec] & 12.045 & 2.440 & 4.090 & 4.167 \\
\cline { 2 - 6 } & Angular freq. [rad/sec] & 0.522 & 2.575 & 1.536 & 1.508 \\
\hline \multirow{2}{*}{$225^{\circ}$} & Period [sec] & 12.838 & 2.435 & 3.979 & 3.970 \\
\cline { 2 - 6 } & Angular freq. [rad/sec] & 0.489 & 2.580 & 1.579 & 1.583 \\
\hline \multicolumn{4}{|c|}{$27.95 \mathrm{~N} / \mathrm{m}$} \\
\hline & Spring constant & \multicolumn{5}{|c}{$3.2 \mathrm{~kg}$} \\
\hline
\end{tabular}

Table 4 Regular wave conditions in the experiment

\begin{tabular}{|c|c|c|c|c|c|c|c|c|c|c|c|}
\hline \multirow{2}{*}{\multicolumn{2}{|c|}{$\begin{array}{l}\text { Regular wave } \\
\text { conditions }\end{array}$}} & \multicolumn{10}{|c|}{ Wave period [sec] } \\
\hline & & 7 & 8 & 9 & 10 & 11 & 12 & 13 & 14 & 15 & 16 \\
\hline \multirow{4}{*}{$\begin{array}{c}\text { Wave } \\
\text { steepness }\end{array}$} & $1 / 50$ & $\mathrm{O}$ & $\mathrm{O}$ & $\mathrm{O}$ & $\mathrm{O}$ & & $\mathrm{O}$ & & & $\mathrm{O}$ & \\
\hline & $1 / 30$ & $\mathrm{O}$ & $\mathrm{O}$ & $\mathrm{O}$ & $\mathrm{O}$ & $\mathrm{O}$ & $\mathrm{O}$ & $\mathrm{O}$ & $\mathrm{O}$ & $\mathrm{O}$ & $\mathrm{O}$ \\
\hline & $1 / 16$ & $\mathrm{O}$ & $\mathrm{O}$ & $\mathrm{O}$ & $\mathrm{O}$ & & $\mathrm{O}$ & & & $\mathrm{O}$ & \\
\hline & $1 / 10$ & $\mathrm{O}$ & $\mathrm{O}$ & $\mathrm{O}$ & $\mathrm{O}$ & & $\mathrm{O}$ & & & $\mathrm{O}$ & \\
\hline
\end{tabular}

Table 5 Irregular wave conditions in the experiment

\begin{tabular}{|c|c|c|}
\hline Irregular wave & Condition 1 & Condition 2 \\
\hline $\mathrm{H}_{\mathrm{S}}$ & $13.27 \mathrm{~m}$ & $14.82 \mathrm{~m}$ \\
\hline $\mathrm{T}_{\mathrm{P}}$ & $14.88 \mathrm{sec}$ & $15.54 \mathrm{sec}$ \\
\hline$\gamma$ & 1.93 & 1.95 \\
\hline Heading & $\begin{array}{c}\text { Head sea } \\
\text { Quartering sea }\end{array}$ & $\begin{array}{c}\text { Head sea } \\
\text { Quartering sea }\end{array}$ \\
\hline Remark & 1,000 years & 10,000 years \\
\hline Random seed for wave calibration & $1 \sim 10$ & $1 \sim 10$ \\
\hline Random seed for motion & $1 \sim 5$ & $1 \sim 5$ \\
\hline
\end{tabular}

\subsubsection{Numerical setup}

Bureau Veritas' software HydroStar was used for the cross reference of the experimental results. This software performed calculations based on the three-dimensional potential theory using the boundary elements method (BEM).

The grids of the test model were generated by using Gridgen with quadrilateral panels. A total of 11,840 grids were made (Fig. 8), and two heading conditions, 101 frequency components, and the interval of 6 to $16 \mathrm{~s}$ were divided into equal intervals. The detailed calculation conditions are shown in Table 6.

\subsection{Analysis and result}

\subsubsection{Response amplitude operator (RAO)}

In this experiment, the measured motions of the test model in six degrees of freedom in regular waves with a steepness of $1 / 30$ were compared to the results obtained from the commercial software HydroStar (Bureau Veritas).

Figures 9 and 10 present the RAO for heave, pitch, and roll in the conditions of head sea and quartering sea. Particularly, the black dashed line is the result obtained from HydroStar, and the blue circle shows the RAO calculated from the experimental values. The motion RAO 
was calculated in regular waves using the ratio of the maximum amplitude and incident wave for each motion mode, and the values can be calculated for all frequency components.

In the case of heave, it can be seen that in general, it is similar for each heading, and in the cases of pitch and roll, differences range from 0.4 to $0.6 \mathrm{rad} / \mathrm{s}$, but their relative errors are within about $15 \%$.

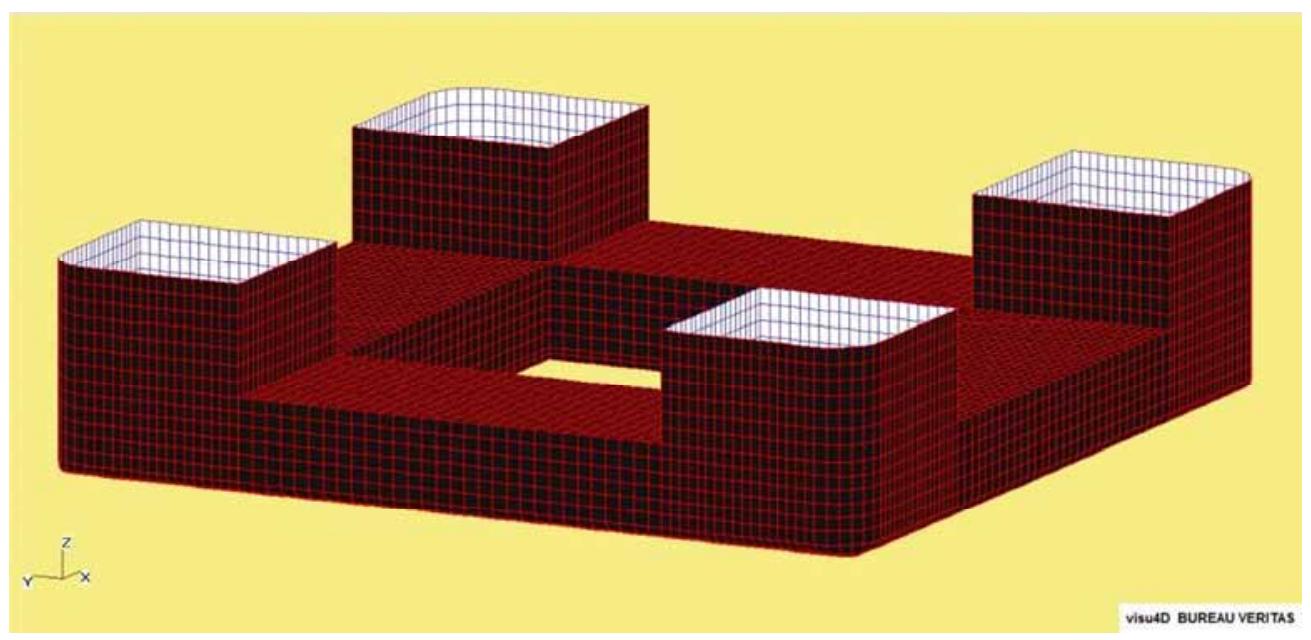

Fig. 8 Mesh information of the TLP model

Table 6 Numerical condition for calculation

\begin{tabular}{|c|c|}
\hline Model type & Tension Leg Platform \\
\hline Panel type & Quadrilateral panel \\
\hline Calculation target & Radiation problem \\
\hline Number of panels on hull & 11,840 \\
\hline Incidence wave angles & $180^{\circ}$ (Head sea) \\
& $225^{\circ}($ Quartering sea $)$ \\
\hline Number of frequencies & $101(6 \sim 16 \mathrm{sec})$ \\
\hline
\end{tabular}
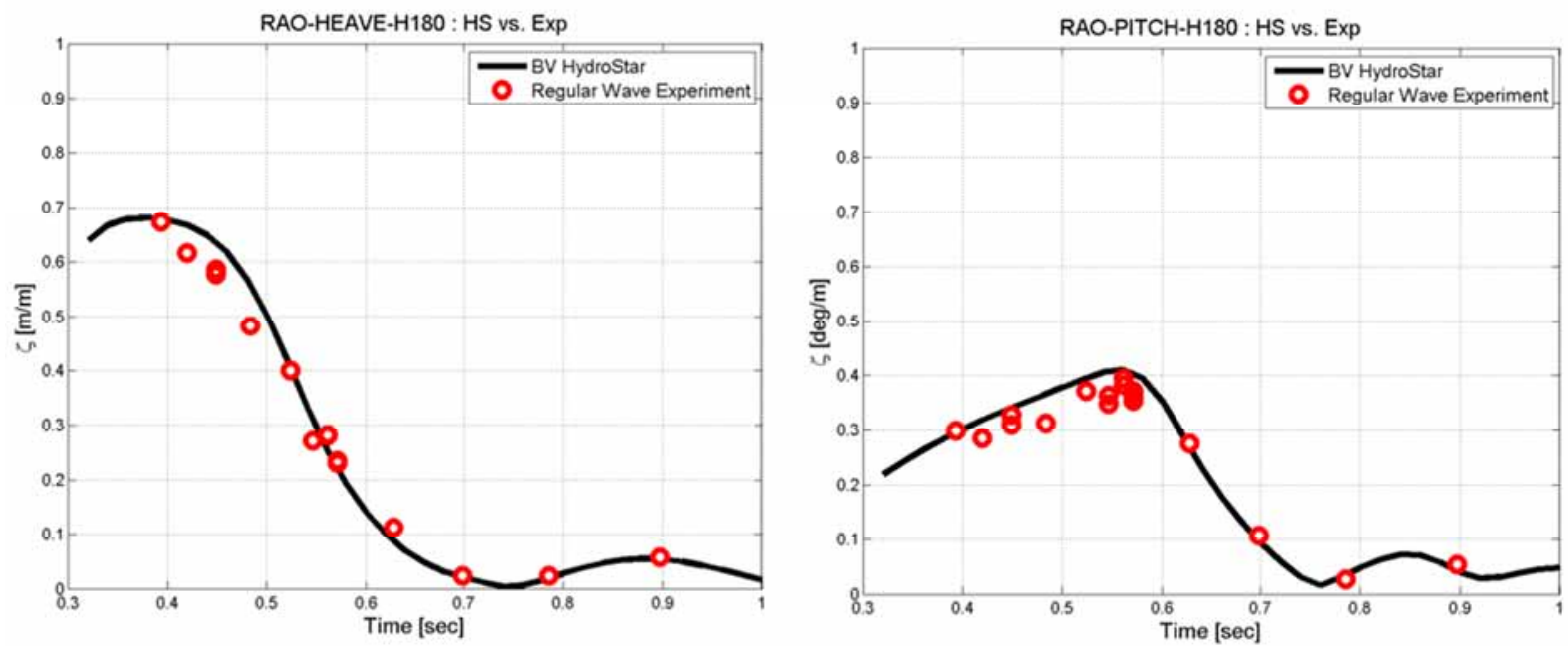

Fig. 9 Heave and pitch RAO, head sea condition 

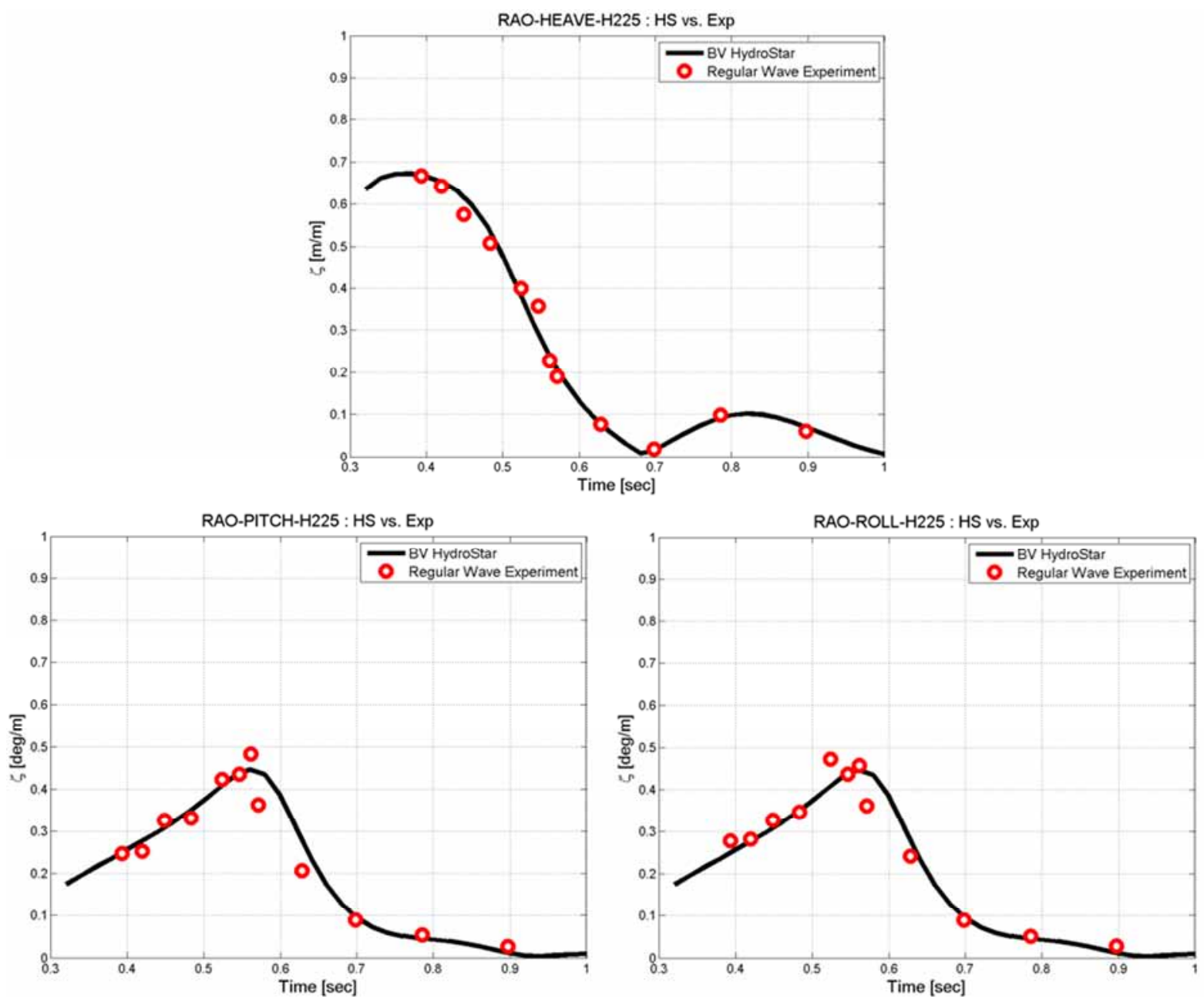

Fig. 10 Heave, roll and pitch RAO, quartering sea condition, according to the clockwise direction from top

\subsubsection{Prediction of irregular wave based on measurement}

For the quantitative analysis of irregular waves, two wave gauges were installed for wave calibration, as seen in Fig. 11. The wave elevation values measured by ten random seeds (seeTable 5) and two environmental conditions were compared to the spectral analysis results obtained from a stochastic process. For the environmental condition 1, the data on irregular waves in the time series collected by wave gauges 1 and 2 are shown in Fig. 12, and the experiments were done in 20-min intervals. The figure only depicts seed \#1 with condition 1 , and the remaining conditions with seeds \#2 to \#10 have been omitted.

Using 10 random seeds for conditions 1 and 2, 20 cases of irregular waves were generated. Figure 13 shows the results of the spectral analysis of the irregular wave generated by using the first random seed in condition 1 and other seeds have been omitted. The spectral analysis was carried out by using Welch's method, with the Hamming window and the appropriate number of overlaps.

Yang [7] was introduced for wave prediction. Using the data collected only with the wave gauge in position \#1 (Fig. 11), the wave was predicted at position \#2, which was separated by $4.5 \mathrm{~m}$ in the direction of the incidence wave, and it was compared to the actual wave measured at position \#2. In addition, by calculating the predictable area in Yang [7], the accuracy of wave predictions within the corresponding range was confirmed. Figure 14 presents the prediction result for random seed \#1 of condition 1, representing other conditions too. The prediction accuracy was represented by relative errors using internal values in the boundary of the predictable area, and the result is shown in Table 7 . The results show that all errors are within $10 \%$. 


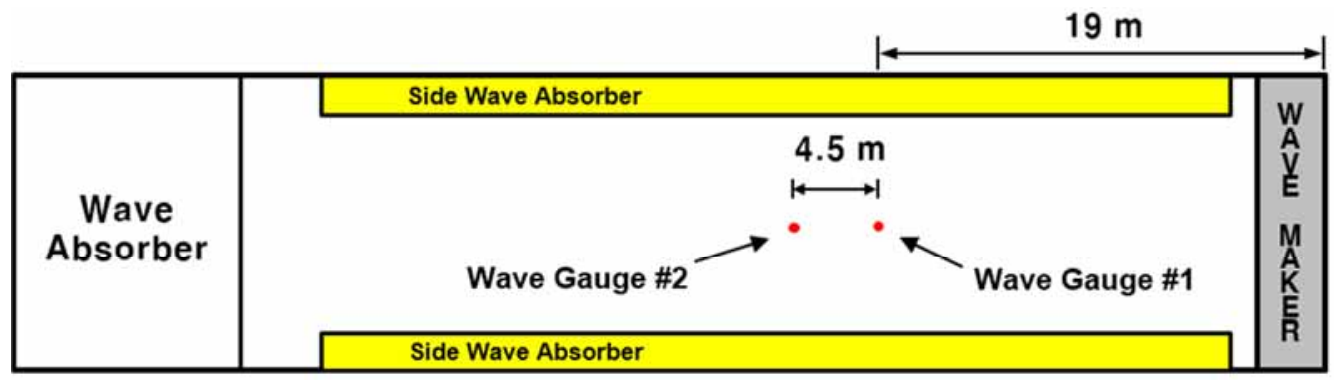

Fig. 11 Wave gauge set-up for calibration and pre-testing
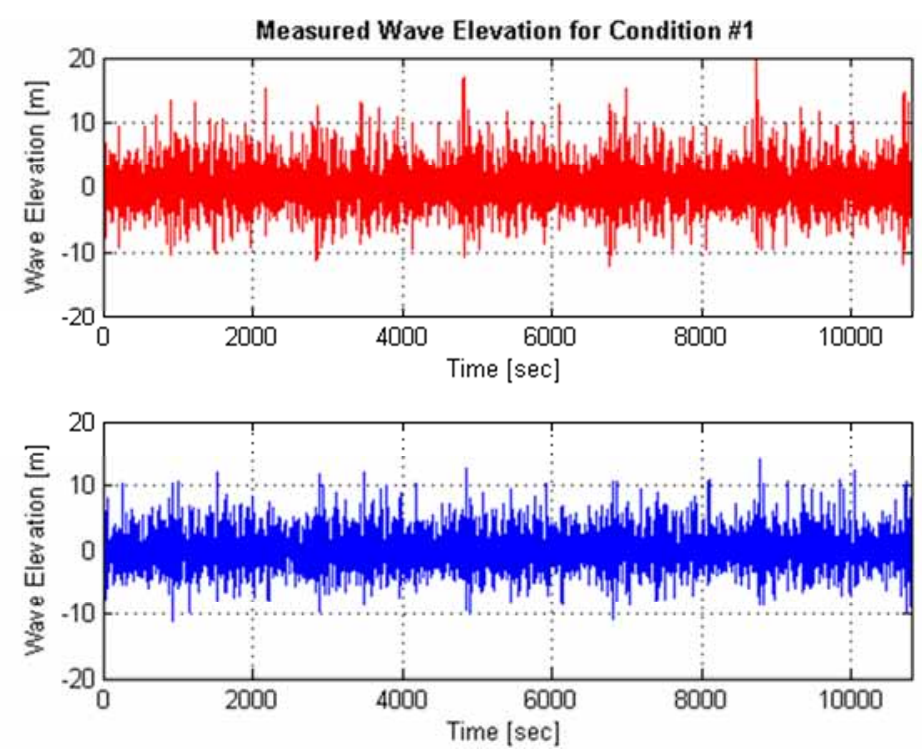

Fig. 12 Time series measurements made at gauge positions \#1 and \#2 under condition 1 (random seed \#1) - the red dashed line is the measured wave at gauge position \#1, and the blue dashed line is the measured wave at gauge position \#2

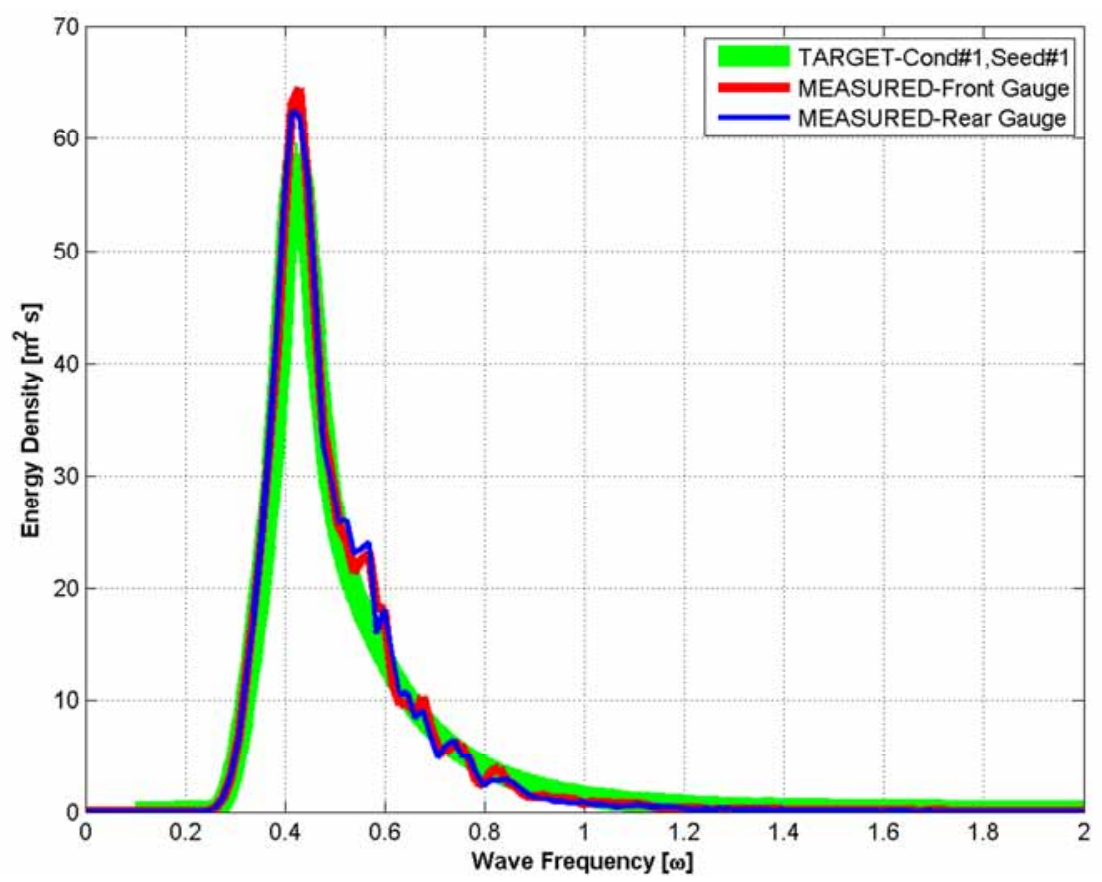

Fig. 13 Spectral analysis results under condition 1 (random seed \#1) - the green dashed line is the input wave condition, the red dotted line is the wave spectrum of its irregular wave at gauge position \#1, and the blue dotted line is the wave spectrum of its irregular wave at gauge position $\# 2$. 


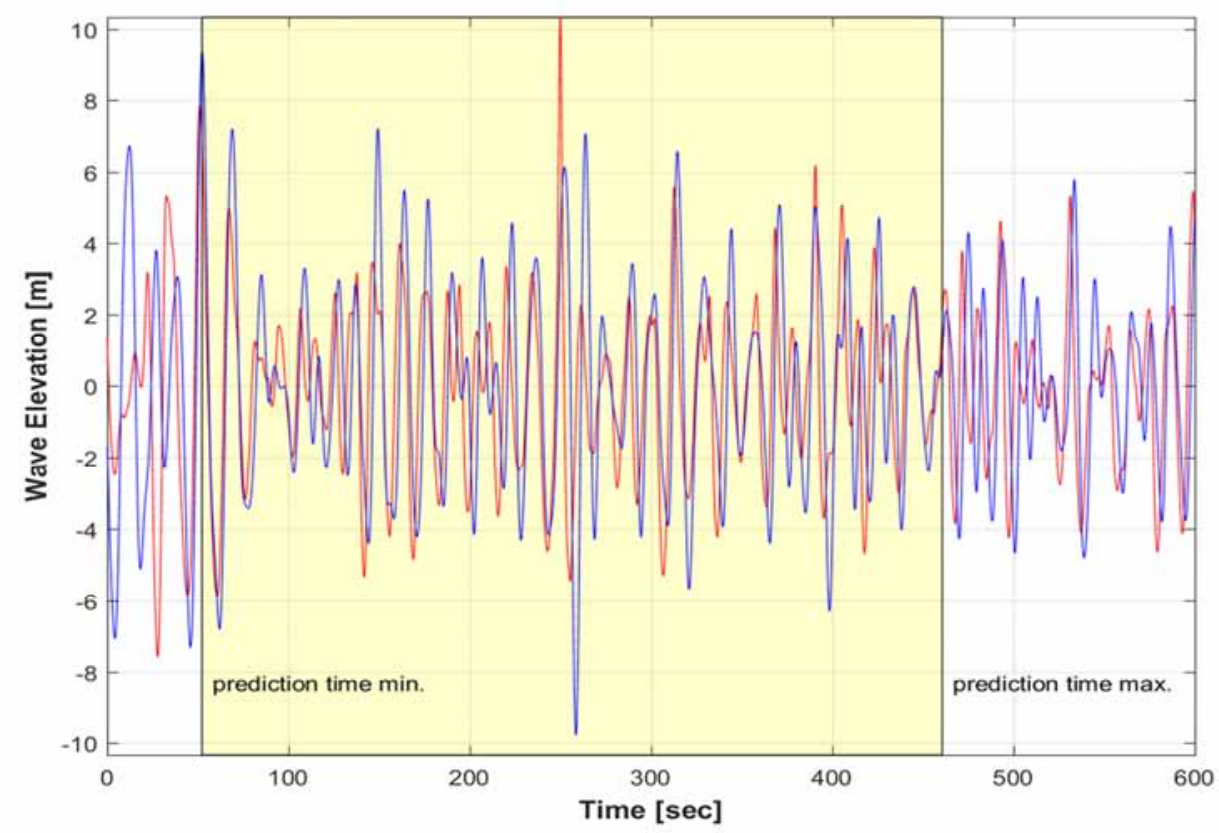

Fig. 14 Comparison between the predicted wave at gauge position \#2 (blue line) based on the irregular wave measurements at gauge position \#1 and the measured wave at gauge position \#2 (red line) under condition1seed\#1

Table 7 Relative error between the predicted and the measured wave at gauge position \#2

\begin{tabular}{|c|c|c|c|c|c|c|c|c|c|c|c|}
\hline \multicolumn{2}{|c|}{$\begin{array}{c}\text { Relative } \\
\text { error [\%] }\end{array}$} & \multicolumn{10}{|c|}{ Random seeds \# } \\
\cline { 2 - 12 } & 1 & 2 & 3 & 4 & 5 & 6 & 7 & 8 & 9 & 10 \\
\hline \multirow{2}{*}{ Conditions } & $\# 1$ & 7.32 & 6.55 & 8.48 & 9.54 & 7.56 & 9.66 & 4.17 & 3.37 & 6.46 & 5.98 \\
\cline { 2 - 12 } & $\# 2$ & 5.27 & 4.71 & 3.11 & 6.56 & 8.75 & 7.58 & 5.57 & 7.44 & 4.97 & 3.38 \\
\hline
\end{tabular}

\subsubsection{Prediction of floating body motion using predicted wave information}

For motion predictions using irregular wave measurements, the wave-to-wave prediction algorithm (Yang [9]) and eq. (8) are used in Section 2.2. In other words, the deterministic phase information obtained from the calculation of the prediction composes eq. (8), and the motions of floating bodies are predicted by using the time domain approach in Section 2.2. The predicted motions of floating bodies are compared to actual motion data measured by a non-contact motion measuring device. Due to the nature of the TLP form, only the heave and roll (pitch) modes are examined for head sea and quartering sea.

For the TLP motion experiment, random seeds shown in Table 5 were used, and these were the same seeds that were used in the wave calibration. The TLP's hydrodynamic coefficient of the time domain approach was calculated by HydroStar. For the quantitative analysis of irregular waves and motion, one wave gauge and one floating body were installed for the experiment, as can be seen in Figs. 15 and 16.

Figure 17 shows motion prediction results for head sea/condition 1/random seeds \#1, and Figure 18 shows the results for the quartering sea condition. The motion prediction accuracy is represented by the values within the boundaries of the predictable area, as in the wave prediction, and the results are shown in Table 8 . The results show that all errors are 
within $10 \%$. Due to the difficulty in representing the entire measurement time of $1,200 \mathrm{~s}$ in the plot, the paper gives the measurement time of only about $400 \mathrm{~s}$.

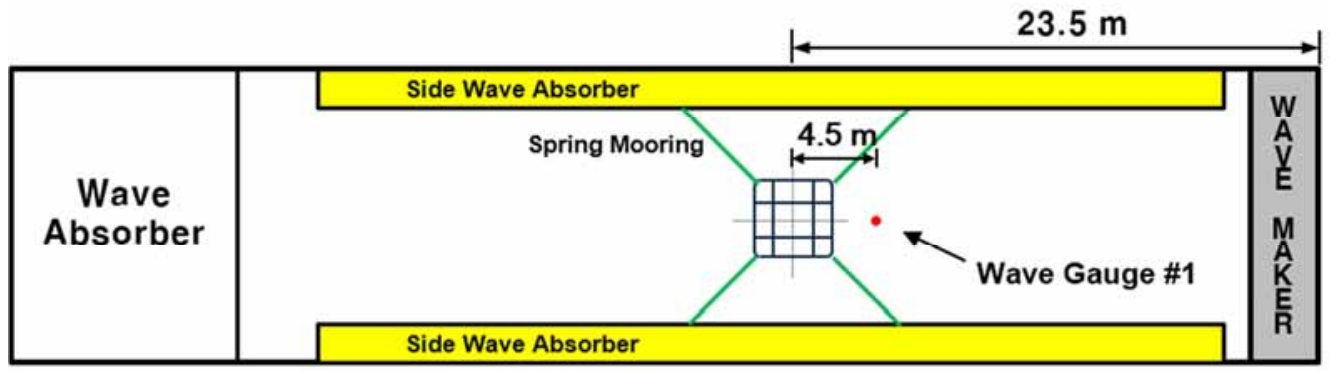

Fig. 15 Wave gauge and floating body experimental set-up for head sea condition

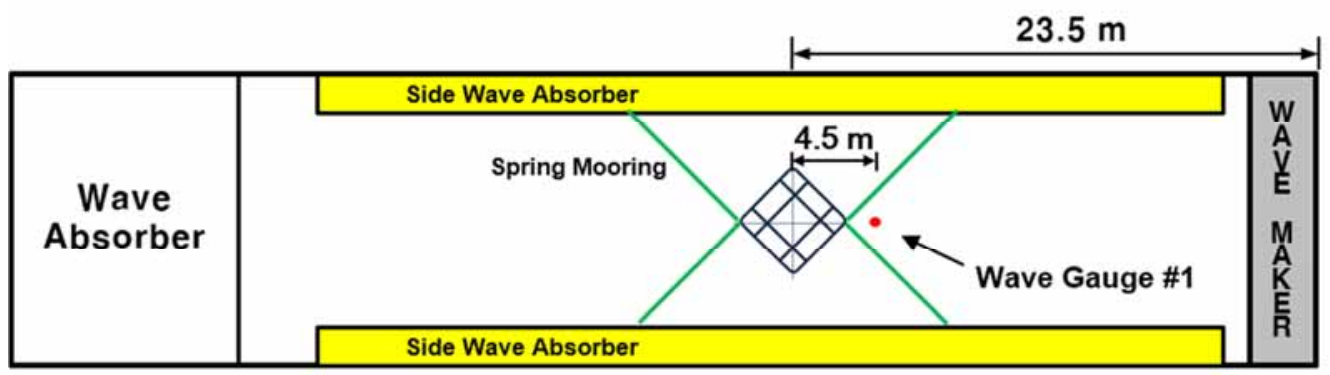

Fig. 16 Wave gauge and floating body experimental set-up for quartering sea condition

Table 8 Relative error between the predicted and the measured motion

\begin{tabular}{|c|c|c|c|c|c|c|c|c|c|c|c|}
\hline \multirow{2}{*}{$\begin{array}{c}\text { Relative } \\
\text { error [\%] }\end{array}$} & \multicolumn{10}{|c|}{ Random seeds \# } \\
\cline { 2 - 12 } & 1 & 2 & 3 & 4 & 5 & 6 & 7 & 8 & 9 & 10 \\
\hline \multirow{2}{*}{ Conditions } & $\# 1$ & 8.54 & 9.47 & 5.56 & 4.16 & 7.88 & 9.45 & 6.34 & 10.35 & 5.98 & 3.37 \\
\cline { 2 - 12 } & $\# 2$ & 7.89 & 5.68 & 6.69 & 7.46 & 8.58 & 6.17 & 3.52 & 8.68 & 4.71 & 7.83 \\
\hline
\end{tabular}




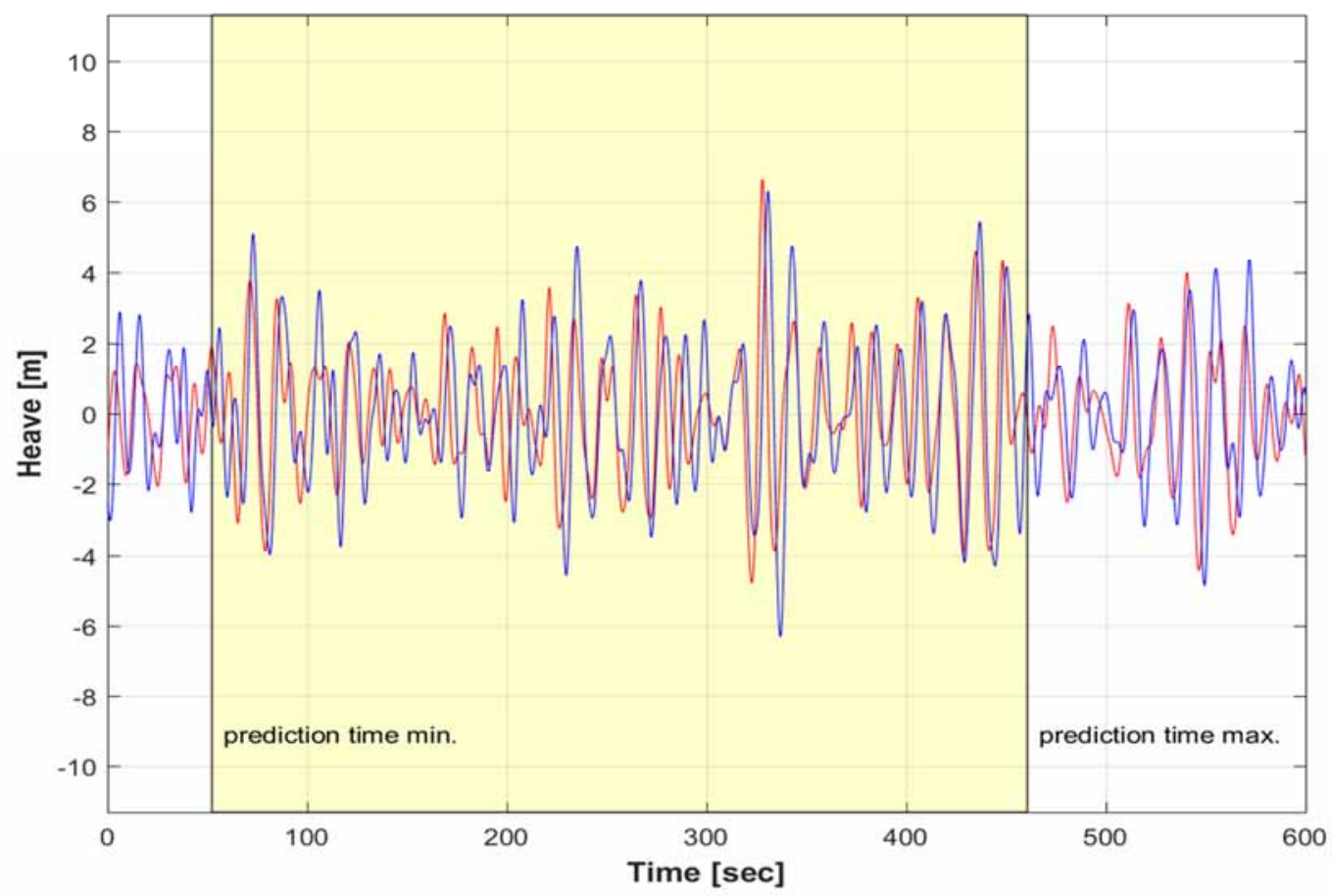

(a) Heave motion

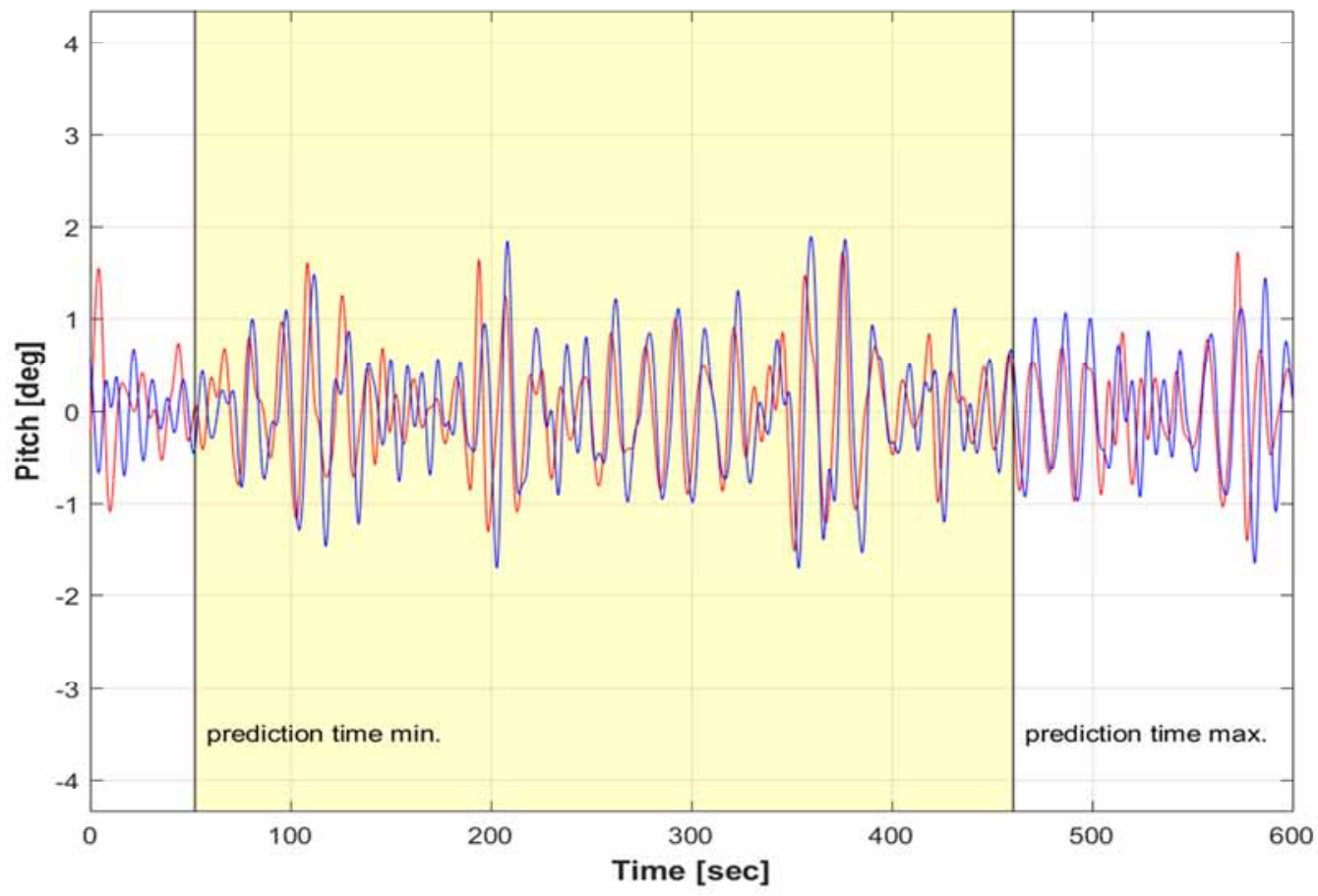

(b) Pitch motion

Fig. 17 Motion prediction based on wave information at gauge position \#1 under head sea/condition 1/random seed \#1 with (a) heave, and (b) pitch motion. The red dashed line depicts the result of motion prediction and the blue dashed line depicts the measured motion. 


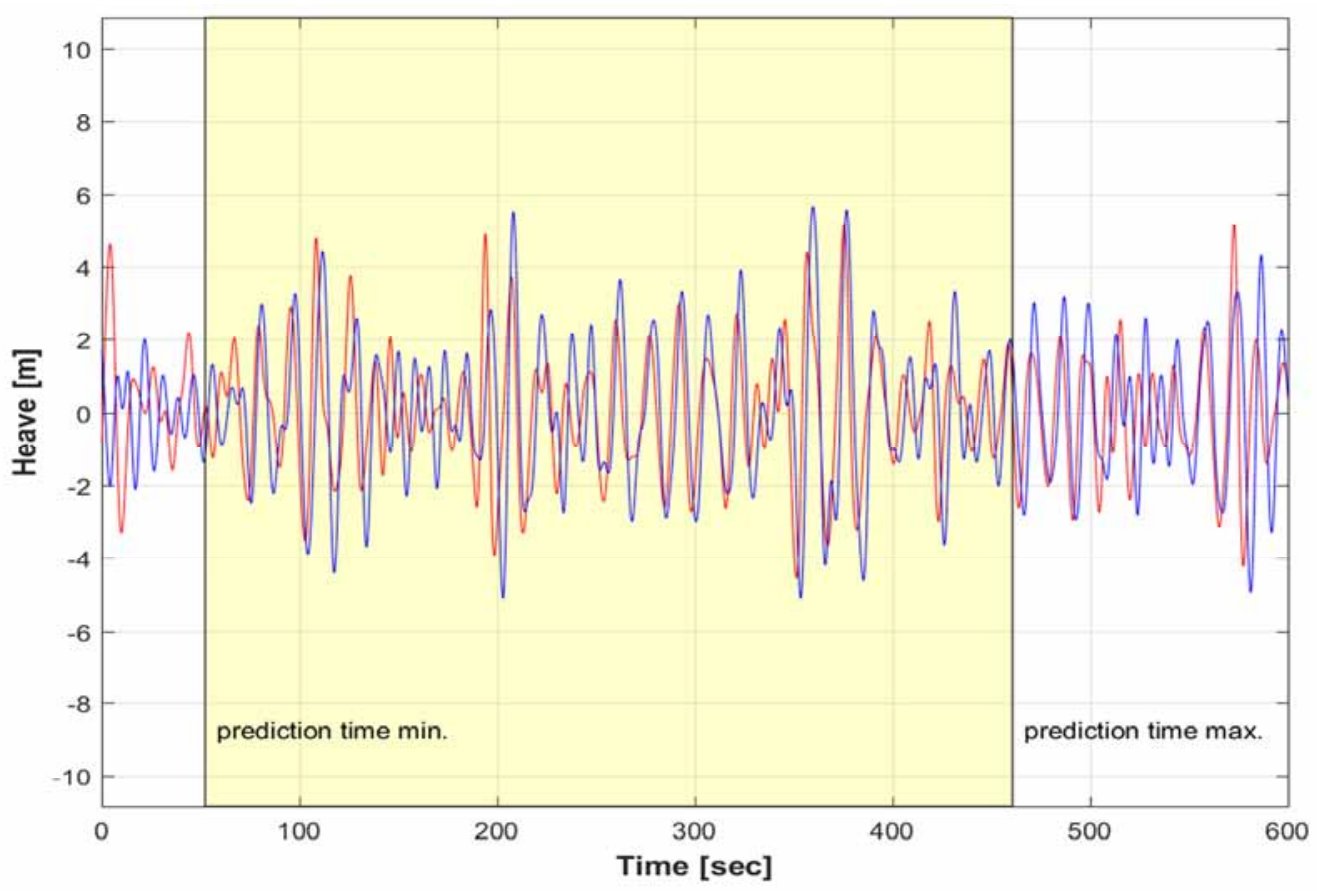

(a) Heave motion

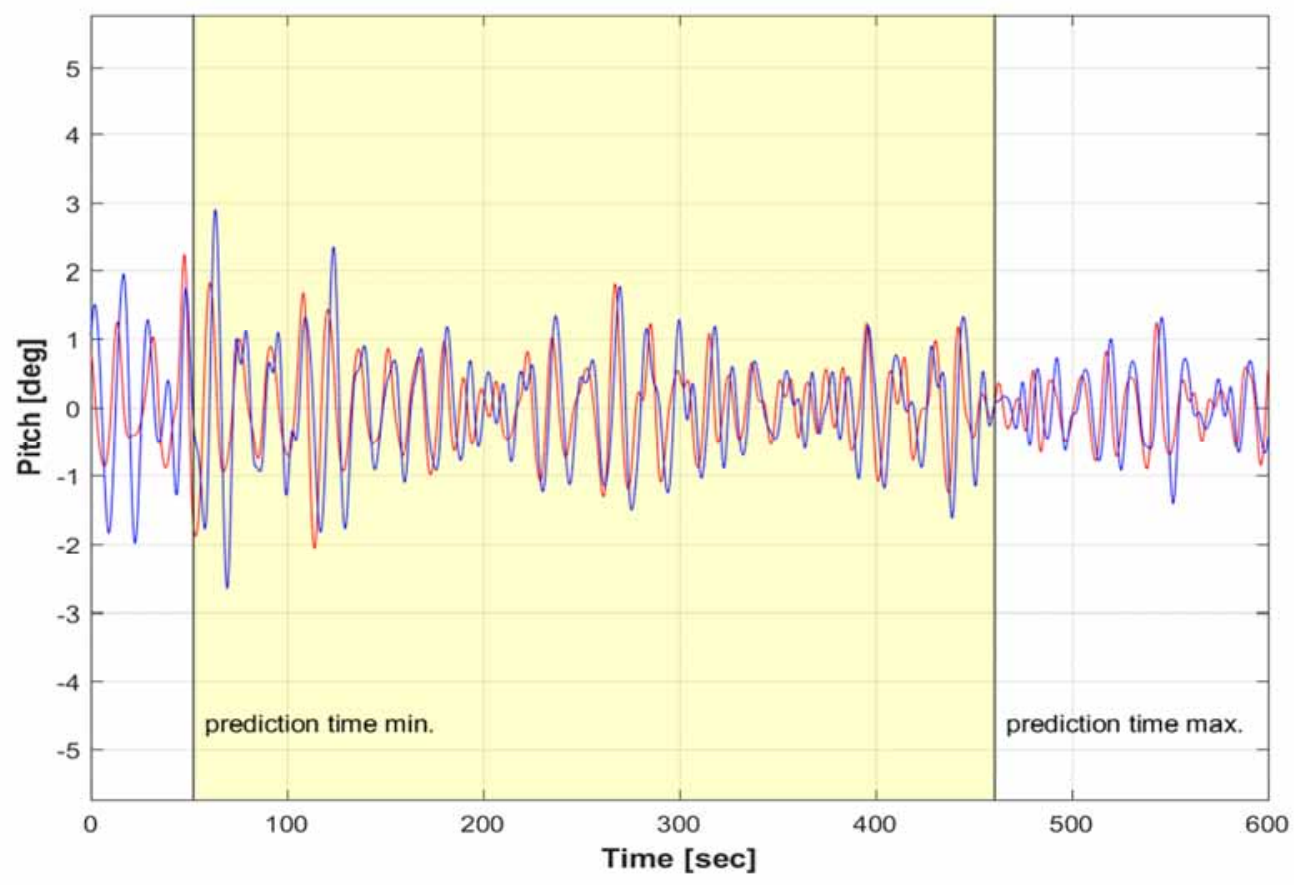

(a) Pitch motion

Fig. 18 Motion prediction based on wave information at gauge position \#1 under quartering sea/condition 1/random seed \#1 with (a) heave, and (b) pitch motion. The red dashed line depicts the result of motion prediction and the blue dashed line depicts the measured motion.

\section{Concluding remarks}

The Cummins method was introduced for the time domain motion analysis to determine whether or not the retardation function converged, and it was introduced into the equation of motion. In particular, roll motions are sensitive to viscous damping, so caution is needed in calculations. 
To combine wave predictions and floating body motions when the exciting force is extended into the time domain, the above presented wave data (Figs. 15 and 16), in the direction of the incident wave, were used to obtain the deterministic phase, confirming the potential of predicting the mode of each motion. In particular, we believe we have obtained the credibility required in practical applications, because errors in the predictable area were within $10 \%$.

In this study, we developed and verified an algorithm that can predict the motion of a floating body based only on the wave elevation information (Figs. 15 and 16), in the incident wave direction. In real life situations, sailing vessels and floating bodies are equipped with an $\mathrm{x}$-band radar, so they can measure incident wave time series in real time. Based on this, we believe it is possible to calculate the deterministic phase and predict ship motions. This type of technology may solve problems related to motion stability directly, such as parametric rolling, if it is introduced to container ships, Ro-Ro vessels, and bulk carriers. Ultimately, it is expected to help prevent or minimize casualties on not only floating bodies that use helidecks, but also vessels on which helicopter landing and take-off is frequent, as well as passenger ships, ensuring ship safety. Therefore, we expect this technology to be applied to solve a variety of realistic problems.

\section{ACKNOWLEDGEMENT}

This work was supported by the National Research Foundation of Korea (NRF) grant funded by the Korea government (MSIP) through GCRC-SOP (No. 2011-0030013). This research was supported by a grant by the LNG Plant R\&D Center which belongs to the Plant Research Program funded by the Ministry of Land, Infrastructure and Transport (MOLIT) of the Korean government. This work was also funded by the Korea Meteorological Administration Research and Development Program under Grant KMIPA 2014-22010. This paper was written based on the $\mathrm{PhD}$ thesis.

\section{REFERENCES}

[1] Cummins, W. E., 1962, The impulse response function and ship motions. Symposium on Ship Theory, Hamburg, Germany, Schiffstechnik 9, 101-109.

[2] Söding, H., 'Prediction of Ship Steering Capabilities' Schiffstechnik, 29:3-29, 1982.

[3] Symon, K. R., Mechanics, 1971.

[4] Journée, J. M. J., Fluid Tanks and Ship Motions, Lecture Note - held at Kyushu University, 2000.

[5] Lee S.J., The Effects of LNG-Sloshing on the Global Responses of LNG-Carriers, Ph. D. Thesis, Texas A\&M University, 2008.

[6] Clauss G., Kosleck S., and Testa D., Critical Situations of Vessel Operations in Short Crested SeasForecast and Decision Support System, International Conference on Offshore Mechanics and Arctic Engineering, 4, 319-332, 2009. DOI: 10.1115/omae2009-79482

[7] Kosleck S., Prediction of Wave-Structure Interaction by Advanced Wave Field Forecast, PhD Thesis, Technische Universität Berlin, 2013.

[8] Gilat, A., Subramaniam, V., Numerical Methods, 2010.

[9] Yang. Y. J., Real Time Ship Motion Prediction with Wave Monitoring, Ph. D Thesis, Pusan National University, 2015.

$\begin{array}{ll}\text { Submitted: } & 23.11 .2015 \\ \text { Accepted: } & 20.9 .2016\end{array}$

\author{
Young Jun Yang ${ }^{1}$ \\ ybihong@pusan.ac.kr \\ Sun Hong Kwon ${ }^{2}$ \\ shkwon@pusan.ac.kr \\ Department of Naval Architecture and \\ Ocean Engineering, Pusan National \\ University, Geumjeong-gu, Busan, 46241, \\ Republic of Korea (South Korea)
}

